\title{
Effects of Polyunsaturated Fatty Acids (PUFA) Supplementation on Reproductive Performance of Beef Heifers Submitted to Fixed-time Artificial Insemination (FTAI) Protocol
}

\author{
João Batista Souza Borges, Andressa Varella Gonsioroski \& Eduardo Pradebon da Silva
}

\begin{abstract}
Background: More recently, polyunsaturated fatty acids (PUFA) supplements have been used in grazing beef herds in attempt to influence specific metabolic pathways and hormones that directly modulate reproductive function. Supplementation of calcium salts of PUFA can positively influence ovarian follicular growth, luteal function, and improve reproductive performance in dairy and beef females. The aim of this experiment was to evaluate strategies of dietary treatments using PUFA supplementation for 30 days before or after FTAI protocol and its effects on of ovulatory follicle size, ovulation, pregnancy and gestational losses rates in beef heifers.

Materials, Methods \& Results: One hundred and ninety-nine Brangus heifers $(24 \pm 3$ months-old; BW= $320 \pm 15 \mathrm{~kg}$; $\mathrm{BCS}=2.85 \pm 0.17)$ were randomly assigned in three different groups to receive dietary treatments. Group $1(\mathrm{n}=70)$ was fed with $0.5 \mathrm{~kg} /$ day of a protein-mineral mixture supplement containing $0.2 \mathrm{~kg} /$ day PUFA (Mix A) during 30 days before FTAI, Group $2(n=68)$ received the same supplement 30 days after FTAI and Control $(n=61)$ only the supplement without PUFA (Mix B) during all period. Heifers were submitted to estrous synchronization treatment using progesterone (P4), estradiol benzoate (E2) and prostaglandin $\mathrm{F}_{2 \alpha}$ (PGF). Ultrasound exams were done to measure ovulatory follicle diameter and to determinate ovulation and pregnancy rates on Days 30 and 60 after FTAI. Daily gain (DG) was higher $(P$ $<0.05$ ) only when heifers received supplement containing PUFA (Group $1=30$ days prior FTAI) and (Group $2=30$ days after FTAI). PUFA supplementation before FTAI also resulted in larger ovulatory follicles diameter $(P<0.05)$ in Group $1(11.2 \pm 2.5 \mathrm{~mm})$ compared to Group $2(9.9 \pm 2.3 \mathrm{~mm})$ and Control $(10.0 \pm 2.07 \mathrm{~mm})$. Ovulation rates were similar $(P>$ $0.05)$ in Group $1(90 \%)$, Group $2(75 \%)$ and Control (67\%). Pregnancy rates were higher $(P<0.05)$ in Group 1 (Day $30=$ $67.1 \%$ and Day $60=64.2 \%$ ) when compared with Group 2 (Day 30=48.5\% and Day $60=44.1 \%$ ) and Control (Day 30= $49.2 \%$ and Day $60=45.9 \%)$. Gestation losses were similar $(P>0.05)$ among Groups $1(6.6 \%), 2(9 \%)$ and Control $(6.6 \%)$. Discussion: Rumen-protected supplemental lipids have been used to increase energy density and to determine direct positive effects on reproduction in dairy and beef herds. There is evidence that feeding moderate amounts of PUFA supplements can improve energy status and result in significant differences in DG as it was observed during experimental period. Thus, heifers that received $0.2 \mathrm{~kg} /$ day of PUFA supplement 30 days before FTAI protocol had also a positive effect on ovulatory follicles size, but ovulation rates were similar in groups. Beneficial effects of pre-breeding PUFA supplementation were observed on pregnancy rates on Days 30 and 60 after FTAI, but pregnancy loss was not different among dietary treatments in beef heifers. Based on this study, PUFA supplementation before FTAI protocol had a positive effect on reproductive performance of beef heifers by directly improving ovarian function, uterine environment and early embryonic development. Results indicate that pre-breeding PUFA supplementation to beef heifers is a suitable strategy to increase pregnancy rate in FTAI programs. Therefore, for a better understanding of interactions of nutritional strategies and utero-ovarian functions more evaluations are needed to understand the mechanisms by which feeding PUFA may improve reproductive function in beef heifers.
\end{abstract}

Keywords: polyunsaturated fatty acids, beef heifers, fixed-time artificial insemination. 


\section{INTRODUCTION}

Fixed-time artificial insemination (FTAI) is an alternative to improve massive use of genetic resources in beef herds. However, pregnancy rates rarely reach values above $55 \%$ in beef heifers under extensivily managed systems. In most cases, inadequate dietary intake and poor body condition score lead to subotimal ovarian activity at the beginning of breeding season limiting success of FTAI programs in beef herds [8-10].

Nutritional management before reproductive period can improve the fertility in domestic ruminants, influencing follicular development, oocyte quality and pregnancy development. Nutritional components such as calcium soaps of fatty acids have been recommended in FTAI programs as an alternative to improve energy diet content and achieve better reproductive eficiency through benefits of systemic action of polyunsaturated fatty acids (PUFA) present in its composition [2-4,21]. Several studies describe the positive effects of PUFA supplemetation on size of dominant follicles and ovulation $[11,16]$, size and function of the corpus luteum $[4,12,14]$ and oocyte quality [2,7]. In addition, other authors have also observed that diets containing fatty acids improved embryonic quality [3] and circulating steroid hormones concentrations $[4,13,14]$. Higher plasma progesterone concentration prepares the uterine environment conditions, improving embryonic development, interferon- $\tau$ production and maternal recognition of pregnancy $[1,15,20]$.

We hypothesized that feeding beef heifers with $0.2 \mathrm{~kg} /$ day of PUFA supplementation 30 days before or after FTAI would affect positively ovulatory follicle size, ovulation and pregnancy rates and reduce gestation losses.

\section{MATERIALS AND METHODS}

Local

This experiment was conducted at the Agronomic Experimental Station of the Federal University of Rio Grande do Sul, in the city of Eldorado do Sul, physiographic region of the Central Region of Rio Grande do Sul state.

\section{Animals, diets, and management}

One hundred ninety-nine Brangus heifers 24 \pm 3 months-old, $320 \pm 15 \mathrm{~kg}$ of body weight (BW), mantained on pasture with stocking rate $300 \mathrm{~kg} / \mathrm{ha}$ and forage availability was estimated at $1000 \mathrm{~kg} / \mathrm{ha}$ of dry matter during the period. The initial of body condition score (BCS) was $2.85 \pm 0.17$, based on 1 to 5 scale.
A rumen-protected PUFA source (Megalac- $\left.\mathrm{E}^{\circledR}\right)^{1}$ produced from the saponification process of a soybean oil containing $41.8 \%$ of linoleic acid and $3.6 \%$ linolenic acid was used in a proportion of $40 \%$ in a protein-mineral mixture (Mix A). A protein-mineral mixture containing only soybean meal, wheat bran and mineral salt (Mix B) without PUFA source was used before (Group 2), after (Group 1) FTAI and in all periods for Control heifers. Composition of different mixtures offered during the experiment period (Mix A and Mix B) are presented in Table 1.

Table 1. Composition of protein-mineral supplements (Mix A and Mix B) offered during the experimental period.

\begin{tabular}{ccc}
\hline Ingredient & $\begin{array}{c}\text { Mix A } \\
\% \text { DM}^{*}\end{array}$ & $\begin{array}{c}\text { Mix B } \\
\% \text { DM}^{*}\end{array}$ \\
\hline Soybean meal & 20 & 30 \\
Megalac-E & 40 & 0 \\
Wheat bran & 30 & 60 \\
Mineral salt & 10 & 10 \\
\hline Total & 100 & 100 \\
\hline
\end{tabular}

*DM: Dry matter.

\section{Experimental groups}

Heifers were randomly assigned into three groups. Group 1 heifers $(n=70)$ received Mix A containing $0.2 \mathrm{~kg}$ of PUFA for 30 days before FTAI, and after that the Mix B for 30 days. Group 2 heifers ( $\mathrm{n}=$ 68) were treated in the opposite way, receiving the Mix $\mathrm{B}$ before FTAI and Mix A containing $0.2 \mathrm{~kg}$ of PUFA after FTAI. Control group $(n=61)$ received only Mix B during all period. Heifers were maintained on pasture with free access to mineral salt and water.

Heifers were weighed at the beginning of the experiment (Day -30), on FTAI (Day 0) and at the end of the supplementation management and pregnancy diagnosis (Day 30). Daily gain (DG, kg/day/animal) was calculated during the supplementation period.

\section{Synchronization of estrous cycle and FTAI}

Heifers were submitted to estrous synchronization treatment to FTAI (Figure 1) using a progesterone (P4) intravaginal device and estradiol (E2). The protocol started with insertion of $1 \mathrm{~g} \mathrm{P} 4$ device $\left(\text { Primer }^{\circledR}\right)^{2}$ associated with injection of $2 \mathrm{mg}$, IM, of estradiol benzoate $\left(\text { Ric-BE }{ }^{\circledR}\right)^{2}$. Seven days later, $\mathrm{P} 4$ devices were removed and heifers received $250 \mathrm{mcg}$, IM, of D-cloprostenol $\left(\text { Prolise }{ }^{\circledR}\right)^{2}$. Twenty-four h later, heifers received $1 \mathrm{mg}$, IM, of EB and were inseminated at fixed-time between 48 to $52 \mathrm{~h}$ after removal of $\mathrm{P} 4$ devices using high quality semen previously evaluated. 


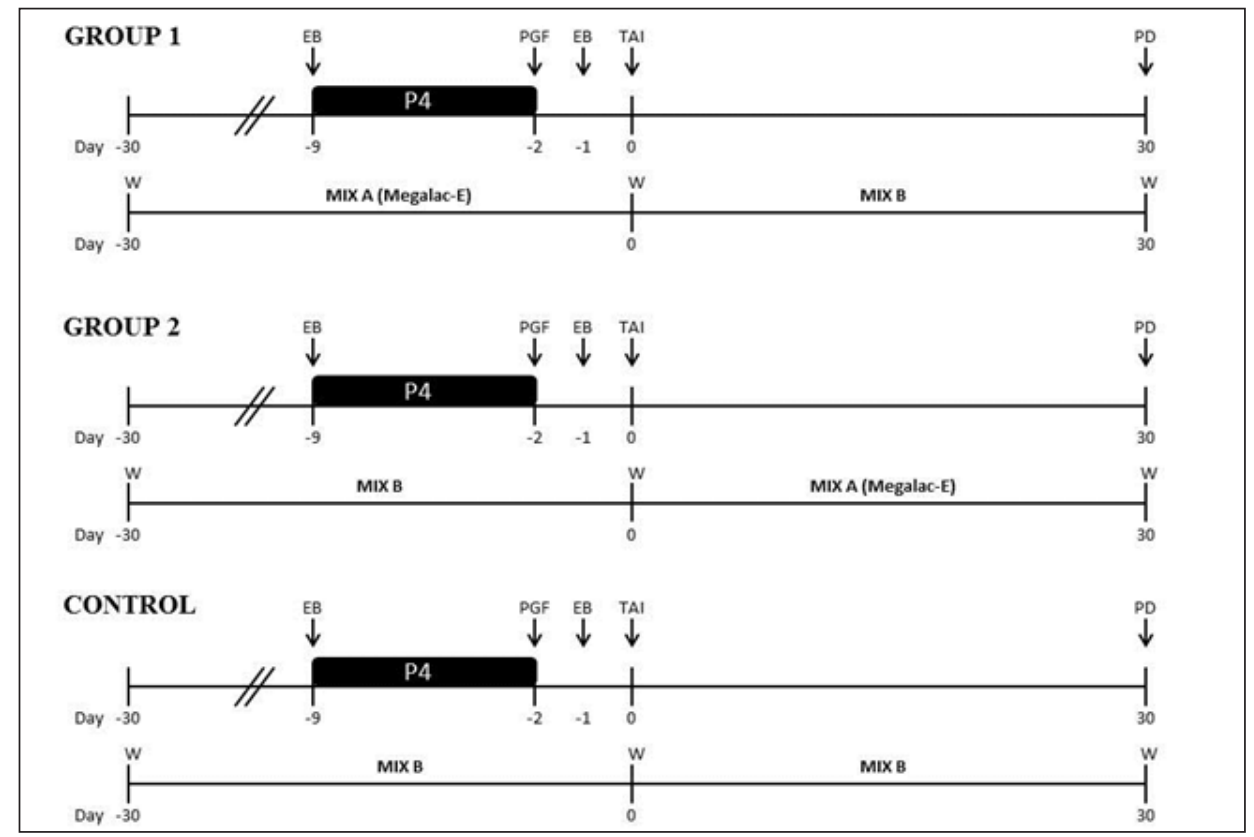

Figure 1. Estrous synchronization treatment to FTAI and feeding scheme of protein-mineral PUFAs supplement to beef heifers. MIX A- $0.5 \mathrm{~kg}$ Protein-mineral supplement containing $0.2 \mathrm{~kg}$ of PUFA source, MIXB - $0.5 \mathrm{~kg}$ Protein-mineral supplement EB - estradiol benzoate, PGF - Prostaglandin, US - ultrasound examination, TAI Timed artificial insemination, P4 - 1 g progesterone intravaginal implant, PD- pregnancy diagnosis, W- weighing.

\section{Ultrasonography}

Subgroups of heifers (Group 1, $\mathrm{n}=30$ ), (Group $2, \mathrm{n}=32$ ) and (Control, $\mathrm{n}=30$ ) had ovaries scanned by ultrasonography (Aquila ${ }^{\circledR}$, linear transretal transducer, 5-7.5 MHz) $)^{3}$ on Day 0 to measure the ovulatory follicle diameter. On Day 1, heifers were examined again to determine the occurrence of ovulation by disappearance the dominant follicle $(\geq 10 \mathrm{~mm})$ previously detected on Day 0. All females were examined for pregnancy diagnosis by ultrasonography 30 and 60 days after FTAI.

\section{Statistical analysis}

Data were analyzed using descriptive statistics. As a measure of central tendency, the median was calculated and on dispersed data minimum and maximum values were calculated. The quantitative variables with normal distribution were analyzed by one-way ANOVA. In addition, the differences of categorical variables such as ovulation and pregnancy rates were analyzed by Chi-square test $\left(\chi^{2}\right)$, considering $P<0.05$ as significant. All analyses were performed using SAS (Statistical Analysis System, version 9.3) ${ }^{4}$.

\section{RESULTS}

Daily gain

Average Daily Gain (DG) in periods before (D-30 to D0) and after FTAI (D0 to D30) are presented in Table 2. Daily gain (DG) was higher $(P<0.05)$ in Group $1(0.501 \mathrm{~kg} /$ day $)$ when supplemented with $0.2 \mathrm{~kg}$ of PUFA 30 days prior FTAI compared with Group 2 (0.340 kg/day) and Control (0.404 kg/day). But after FTAI Group 2 heifers had higher $(P<0.05)$ DG $(0.835 \mathrm{~kg} /$ day $)$ than Group $1(0.393 \mathrm{~kg} /$ day $)$ and Control (0.461 kg/day).

Table 2. Daily gain (DG, kg/day) 30 days before TAI (D-30 to D0) and 30 days after TAI (D0 to D30).

\begin{tabular}{ccc}
\hline & $\begin{array}{c}\text { DG D -30 to D 0 } \\
\text { (kg/day) }\end{array}$ & $\begin{array}{c}\text { DG D 0 to D 30 } \\
\text { (kg/day) }\end{array}$ \\
\hline Group 1 & $0.501^{\mathrm{a}}$ & $0.393^{\mathrm{a}}$ \\
Group 2 & $0.340^{\mathrm{b}}$ & $0.835^{\mathrm{b}}$ \\
Control & $0.404^{\mathrm{b}}$ & $0.461^{\mathrm{a}}$ \\
\hline Total & 0.416 & 0.566 \\
\hline
\end{tabular}

$\overline{\mathrm{a}, \mathrm{b}}$ Values with different superscripts in collum differ $(P<0.05)$. Group 1: Heifers offered $0.5 \mathrm{~kg}$ daily of a protein-mineral mix containing addition of $0.2 \mathrm{~kg}$ of PUFA source (Megalac-E $\left.{ }^{\circledR}\right) 30$ days before FTAI (Mix A) and without PUFA source (Mix B) 30 days after FTAI. Group 2: Heifers offered $0.5 \mathrm{~kg}$ daily of a protein-mineral mix without PUFA source (Mix B) 30 days before FTAI and containing addition of $0.2 \mathrm{~kg}$ of PUFA source (Megalac-E ${ }^{\circledR}$ ) 30 days after FTAI (Mix A). Control: Heifers offered 0.5 $\mathrm{kg}$ daily of a protein-mineral mix without PUFA source (Mix B) 30 days before and 30 after FTAI.

Ovulatory follicle, ovulation and pregnancy rates on Day 30 and Day 60

Table 3 summarizes the effects of dietary PUFA supplementation on diameters of ovulatory follicles at FTAI, ovulation within $24 \mathrm{~h}$ after FTAI 
and pregnancy rates on Day 30 and 60. Diameters of ovulatory follicles were $11.2 \pm 2.5,9.63 \pm 2.2$ and 10.0 $\pm 2.0 \mathrm{~mm}$ for Group 1, 2 and Control, respectively. Heifers supplemented with Mix A containing PUFA before FTAI protocol (Group 1) had higher diameter of ovulatory follicle $(P<0.05)$. Ovulation rate was not affected $(P>0.05)$ by dietary treatments (Group $1=$ 90\%, 27/30) (Group $2=75 \%, 24 / 32)$ and (Control= $66.6 \%, 12 / 18)$, and total ovulation rate was $78.7 \%$
(63/80). Pregnancy rates on Day 30 and Day 60 after FTAI were higher $(67.1 \%, 47 / 70$ and $64.2 \%, 45 / 70)$ in Group $1(P<0.05)$, compared with Group 2 (48.5\%, $33 / 68$ and 44.1, 30/68) and Control (49.2\%, 30/61 and $45.9 \%, 28 / 61)$. Overall pregnancy rate on Day 30 was $55.3 \%(110 / 199)$ and $51.7 \%(103 / 199)$ on Day 60. Gestation loss was similar $(P>0.05)$ between dietary treatments (Group 1=4.2\%, 2/47, Group 2=9\%, 3/33 and Control $=6.6 \%, 2 / 30)$.

Table 3. Ovulatory follicle diameter (Mean \pm Standard Deviation), ovulation and pregnancy rates at 30 and 60 days after FTAI in beef heifers supplemented with PUFAs

\begin{tabular}{ccccc}
\hline & $\begin{array}{c}\text { Ovulatory follicle } \\
(\mathrm{mm})\end{array}$ & $\begin{array}{c}\text { Ovulation rate } \\
\%(\mathrm{n} / \mathrm{n})\end{array}$ & $\begin{array}{c}\text { Pregnancy rate } \\
\text { Day 30 } \\
\%(\mathrm{n} / \mathrm{n})\end{array}$ & $\begin{array}{c}\text { Pregnancy rate } \\
\text { Day 60 } \\
\%(\mathrm{n} / \mathrm{n})\end{array}$ \\
\hline Group 1 & $11.2 \pm 2.5^{\mathrm{a}}$ & $90(27 / 30)$ & $67.1(47 / 70)^{\mathrm{a}}$ & $64.2(45 / 70)^{\mathrm{a}}$ \\
Group 2 & $9.63 \pm 2.2^{\mathrm{b}}$ & $75(24 / 32)$ & $48.533 / 68)^{\mathrm{b}}$ & $44.1(30 / 68)^{\mathrm{b}}$ \\
Control & $10.0 \pm 2.0^{\mathrm{b}}$ & $66.6(12 / 18)$ & $49.2(30 / 61)^{\mathrm{b}}$ & $45.9(28 / 61)^{\mathrm{b}}$ \\
Total & $10.2 \pm 2.2$ & $78.7(63 / 80)$ & $55.3(110 / 199)$ & $51.7(103 / 199)$ \\
\hline
\end{tabular}

a,b Values with different superscripts in the collum differ $(P<0.05)$.

\section{DISCUSSION}

Supplementing PUFA prior or during the breeding season can be a strategy to increase energy density and improve DG and pregnancy rate in beef heifers. In the present study, positive effect of addition of PUFA in the diet resulted in a higher DG in heifers when supplemented with PUFA (Mix A). Feeding of supplemental fat increase propionic acid production and propionate:acetate ratio [5], resulting a higher efficiency of energy utilization, energy portioning and consequently a positive effect on DG. Although there is evidence that feeding fatty acids improve energy status of beef heifers, an enhanced reproductive performance may occur apart from energy balance [6]. Increased serum concentration of insulin, insulin growth factor-I (IGF-I) and Growth hormone (GH) were observed in response to PUFA supplementation in beef cows playing a role in follicular development [16].

In previous studies $[4,11,15]$ larger sizes of ovulatory follicles were observed in cows fed with rumen-protected PUFA supplementation. Changes in follicular dynamics were affected by PUFA supplementation resulting potential alterations in ovarian sensivity to hormones such as IGF-I and gonadotrophins (FSH and LH) $[13,17,20]$. Thus, improvement in reproductive performance of beef heifers depends on stimulation of ovarian activity before FTAI program $[6,8]$. These finds can explain why Group1 heifers supplemented with PUFA before FTAI protocol presented larger diameter of ovulatory follicles and higher pregnancy rate when compared to Group 2 and Control. Results observed in this study, indicate that pre-breeding PUFA supplementation is more effective to improve reproductive performance in beef heifers. In dairy cows, previous studies also observed that supplementation with PUFA determined larger dominant follicles compared to non-supplemented (16.9 and $14.1 \mathrm{~mm}$ ) and $(16.5$ and $15.0 \mathrm{~mm})[15,18]$. The highest frequency of ovulation in the period up to $24 \mathrm{~h}$ after $\mathrm{AI}$, is related to synchronization protocol efficiency and is reflected in improved pregnancy rates. In this study, although heifers supplemented with PUFA before FTAI program had larger ovulatory follicles, ovulation rate was not different among dietary treatments.

Several studies determined that lipid supplementation would improve pregnancy rate in dairy and beef cows [8-10,18,20], however results are still controversial and further studies are required to understand the influence fat diets in reproductive programs of beef heifers [4,7]. In Bos indicus suckled cows supplemented with a source PUFA $(0.1 \mathrm{~kg} /$ day $)$ for 39 days starting at the synchronization protocol to FTAI, it was observed $11 \%$ higher pregnancy rate than control cows $[9,10]$. This data shows that the ef- 
fect of fat supplements on fertility is not only due to the improvement in the energy balance, but also by the specific effect of dietary fatty acids on the axis of hypothalamic-pituitary-ovarian and uterus $[15,16]$.

Addition of PUFA in beef cows diet resulted in elevation of serum cholesterol, a primary substrate to progesterone synthesis, allowing an increase in synthesis of this hormone and reduction in liver metabolization [17] and consequently higher levels of progesterone and chance of pregnancy $[12,18,19]$. It is well established that progesterone concentration plays a major role in stimulating endometrial secretions necessary for succesful developmen of early embryo [12]. Progesterone concentration is essential to development of embryo, placenta implantation and maintenance of pregnancy. These physiological processes are related to progesterone secretion in early pregnancy and are responsible for controlling luteal regression. A low level of mid-phase luteal progesterone leads to a stronger release of $\mathrm{PGF}_{2 \alpha}$ from the uterus. Another important factor that may affect the pregnancy establishment is the suppression of secretion of $\mathrm{PGF}_{2 \alpha}$ already observed in other studies [13,18,20] when cows were supplemented with a PUFA source. This effect can potentially result in sustained progesterone release and reduction of embryonic mortality [18,20]. However, in the present study PUFA supplementation did not influence pregnancy loss between Day 30 and Day 60 of gestation.

\section{CONCLUSION}

Results of this study indicate that PUFA supplementation before FTAI protocol has a positive effect on reproductive performance of beef heifers by directly improving ovarian function, uterine environment and establishment of pregnancy. Therefore, a better understanding of how a small amount of calcium salts of PUFA affects reproductive efficiency in beef heifers is required to establish nutrition strategies under field conditions.

\section{MANUFACTURERS \\ ${ }^{1}$ Arm \& Hammer. Rio de Janeiro, RJ, Brazil. \\ ${ }^{2}$ Agenert União Saúde Animal. São Paulo, SP, Brazil. \\ ${ }^{3}$ Pie Medical Imaging. Masstricht, The Netherlands. \\ ${ }^{4}$ SAS Institute Inc. Cary, NC, USA.}

Declaration of interest. None of authors have any conflict of interest to declare. The authors alone are responsible for the content and writing of the paper.

\section{REFERENCES}

1 Ambrose D.J., Kastelic J.P., Corbett R., Pitney P.A., Petit H.V., Small J.A. \& Zalkovic P. 2006. Lower pregnancy losses in lactating dairy cows fed a diet enriched in $\alpha$-linolenic acid. Journal of Dairy Science. 89: 3066-3074.

2 Bilby T.R., Block J., Amaral B.C., Sá Filho O., Silvestre F.T., Hansen, P.J., Staples C.R. \& Thatcher W.W. 2006. Effects of dietary unsaturated fatty acids on oocyte quality and follicular development in lactating dairy cows in summer. Journal of Dairy Science. 89: 3891-3903.

3 Childs S., Carter F. \& Lynch C.O. 2008. Embryo yield and quality following dietary supplementation of beef heifers with n-3 polyunsaturated fatty acids (PUFA). Theriogenology. 70: 992-1003.

4 Childs S., Lynch C.O. \& Hennessy A.A. 2008. Effect of dietary enrichment with either n-3 or n-6 fatty acids on systemic metabolite and hormone concentration and ovarian function in heifers. Animal. 2: 883-893.

5 Fuston R.N. 2004. Fat supplementation and reproduction in beef females. Journal of Animal Science. 82: 154-161.

6 Guardiero M.M., Bastos M.R., Mourão G.B., Carrijo L.H.D., Melo E.O., Rumpf R. \& Sartori R. 2010. Função ovariana de novilhas Nelore alimentadas com dieta suplementada com gordura protegida ruminal. Pesquisa Agropecuária Brasileira. 45: 408-414.

7 Kim M. \& Kinoshita J.Y. 2001. Lipid and fatty acid analysis of fresh and frozen-thawed immature and in vitro matured bovine oocytes. Reproduction. 122: 131-138.

8 Lopes C.N., Vasconcelos J.L.M., Araújo T.P.B. \& Oliveira L.O.F. 2007. Effect of supplementation with Megalac E on pregnancy rate in primiparous Nellore cows. Journal of Animal Science. 85(Suppl. 2): Abstract.

9 Lopes C.N., Scarpa A.B., Cappellozza B.I., Cooke R.F. \& Vasconcelos J.L.M. 2009. Effects of rumen-protected polyunsaturated fatty acid supplementation on reproductive performance of Bos indicus beef cows. Journal of Animal Science. 87: 3935-3943.

10 Lopes C.N., Cooke R.F., Reis M.M., Peres R.F.G. \& Vasconcelos J.L.M. 2011. Strategic supplementation of calcium salts of polyunsaturated fatty acids to enhance reproductive performance of Bos indicus beef cows. Journal of Animal Science. 89: 3116-3124. 
11 Lucy M.C., Staples C.R., Michel F.M. \& Thatcher W.W. 1991. Energy balance and size and number of ovarian follicles detected by ultrasonography in early postpartum dairy cows. Journal of Dairy Science. 74: 473-482.

12 Mann G.E. \& Lamming G.E. 1999. The Influence of Progesterone During Early Pregnancy in Cattle. Reproduction of Domestic Animals. 34: 269-274.

13 Mattos R., Staples C.R. \& Thatcher W.W. 2000. Effects of dietary fatty acids on reproduction in ruminants. Reviews of Reproduction. 5: 38-45.

14 Raes K., De Smet S. \& Demeyer D. 2004. Effect of dietary fatty acids on incorporation of long chain polyunsaturated fatty acids and conjugated linoleic acid in lamb, beef and pork meat: a review. Animal Feed Science and Technology. 13: 199-221.

15 Robinson R.S., Pushpakumara P.G.A., Cheng Z., Peters A.R., Abayasekara D.R.E. \& Wathes D.C. 2002. Effects of dietary polyunsaturated fatty acids on ovarian and uterine function in lactating dairy cows. Reproduction. 124: 119131.

16 Ryan D.P., Spoon R.A. \& Williams G.L. 1992. Ovarian follicular characteristics, embryo recovery, and embryo viability in heifers fed high-fat diets and treated with follicle-stimulation hormone. Journal of Animal Science. 70: 3505-3513.

17 Santos J.E.P., Bilby T.R., Thatcher W.W., Staples C.R. \& Silvestre F.T. 2008. Long chain fatty acids of diet as factors influencing reproduction in cattle. Reproduction of Domestic Animals. 43(Supp. 2): 23-30.

18 Staples C.R., Wiltbank M.C. \& Grummer R.R. 2000. Effect of long chain fatty acids on lactation performance and reproductive tissues of Holstein cows. Journal of Dairy Science. 83: 278.

19 Staples C.R., Burke J.M. \& Thatcher W.W. 1998. Influence of supplemental fats on reproductive tissues and performance of lactating cows. Journal of Dairy Science. 81: 856-871.

20 Thatcher W.W., Meyer M.D. \& Danet-Desnoyers G. 1995. Maternal recognition of pregnancy. Journal of Reproduction \& Fertility. 49: 15-28.

21 Watches D.C., Robert D., Abayasekara E. \& Aitken A. 2007. Polyunsaturated fatty acid in male and female reproduction. Biology of Reproduction. 77: 190-201. 